\title{
Darwinian Selection in Prostate Cancer and Medical Treatment
}

\author{
Chunjiao Song \\ Medical Research Center, Shaoxing People's Hospital/Shaoxing Hospital of Zhejiang University, Shaoxing, China \\ Email: chunjiaosong@163.com
}

How to cite this paper: Song, C.J. (2017) Darwinian Selection in Prostate Cancer and Medical Treatment. International Journal of Clinical Medicine, 8, 353-367.

https://doi.org/10.4236/ijcm.2017.86033

Received: February 1, 2017

Accepted: June 13, 2017

Published: June 16, 2017

Copyright $\odot 2017$ by author and Scientific Research Publishing Inc. This work is licensed under the Creative Commons Attribution International License (CC BY 4.0).

http://creativecommons.org/licenses/by/4.0/

\begin{abstract}
Organisms evolved into different species to adapt to the environment according to the laws of Darwinian evolution. In a single life, prostate cancer cells can also evolve into tumor stem cells to adapt to the microenvironment, such as different chemotherapeutic drugs. These cancer cells become an unrestricted growth group relatively independent of the individual. The present review attempts to establish evidence that prostate cancer cells may survive by hormonotherapy and chemotherapy by gene amplification, mutation, and alternative splicing. Simultaneously, novel treatment strategies have been cited and evaluated, avoiding the resistance mechanisms.
\end{abstract}

\section{Keywords}

Prostate Cancer, Androgen Receptor, Tumor Microenvironment, Darwinian Selection

\section{Introduction}

In Europe and the USA, prostate cancer (PCa) is one of the most common malignant tumors and the second leading cause of cancer-related deaths in men. $\mathrm{PCa}$ is primarily an androgen-dependent tumor that is treated using androgen deprivation therapy (ADT). The androgen receptor (AR) is a key driver molecule leading to the occurrence and progression of PCa, even in the stage of castration-resistant PCa (CRPC). The AR is a multi-domain, ligand-inducible nuclear transcription factor encoded at Xq11-Xq12. It is encoded by eight exons and has four structural domains: the $\mathrm{N}$-terminal transcriptional activation domain (exon 1), the DNA-binding domain (DBD) (exons 2 - 3), a hinge region (exons 3 - 4), and the C-terminal ligand-binding domain (LBD) (exons 4 - 8). The AR may be activated by androgen through binding to LBD of the receptor, then the $A R$ is internalized to the nucleus and interacts with target genes through its conserved DBD binding to androgen-responsive elements (ARE). 
Moreover, AR complex regulates the transcription of its target genes with the help of coactivator and corepressor proteins.

The AR signaling axis (Figure 1, from WikiPathways) is the core of all stages of the PCa pathophysiology and serves as the primary target for endocrine-based therapy [1]. The current treatments for PCa involve inhibitors of androgen production and antiandrogens blocking the interaction between ligands with AR-LBD [2].

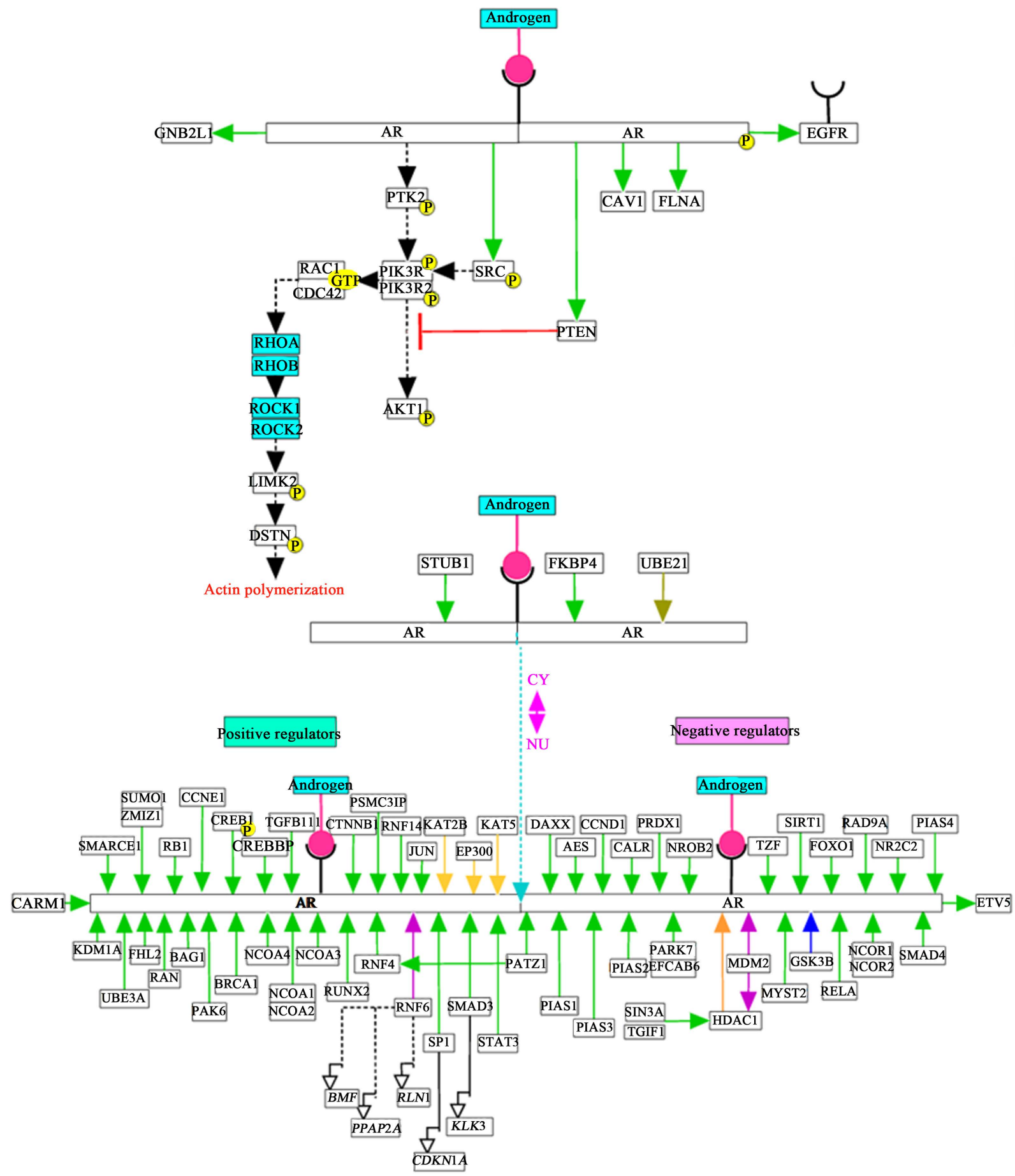

Figure 1. Androgen receptor signaling pathways (Homo sapiens) from WikiPathways. 


\section{Darwinian Selection in the Therapies for Prostate Cancer}

"Natural selection, survival of the fittest" dogma states that species evolve and develop from junior to senior, from simple to complex, from less to more through heredity, mutation, and natural selection. The principal mechanism of evolution, natural selection, has been confirmed by several observations and experiments. Natural selection is an adaptive evolution, i.e., if the variation of species is suitable for the changing environment, then the species will emerge victorious in the struggle for survival; however, if the variation of species is unsuitable for the survival conditions, then it tends to perish.

Darwin's natural selection mainly refers to organisms in the natural world. Nevertheless, the survival mechanism also exists in an independent individual, and similar to Darwin's theory, it constantly affects human health and life, for example, the disposition between PCa and clinical treatments. Although ADT is originally effective in the most PCa patients, the effectiveness is short-lived. Most PCas will progress to the lethal castration-resistant and metastatic phenotype. Genomic alteration, clonal selection, and evolution of the tumor microenvironment will contribute towards unique physiological characteristics under selection pressure. These pressures contain the chemotherapeutic drugs applied in the clinical setting, and the exposures of PCa cells to hormonal stimuli in the tumor microenvironment. AR is a key driver molecule to take part in PCa development and progression, response to initial $\mathrm{ADT}$, and subsequent resistance to chemotherapeutics. These malignant cells undergo several adaptive changes to ensure persistent androgen signaling.

For a long time, docetaxel was the only drug to treat CRPC. Recently, new drugs for CRPC based on different mechanisms have become available, including CYP17A1 inhibitors reducing androgen production and antiandrogens targeting AR signaling. Scientists have found two types of antiandrogens, including the steroidal antiandrogens and the non-steroidal antiandrogens. Among them, the steroidal antiandrogens are limited in clinical use because of their severe side effects and low efficacy. While the non-steroidal antiandrogens include the firstgeneration antiandrogens: nilutamide, bicalutamide, flutamide, and the secondgeneration: enzalutamide and ARN509, etc. These non-steroidal antiandrogens have been widely used clinically due to avoiding the constraints of the steroidal antiandrogens. However, after an initial effective response, approximately 50\% of the PCa patients recurred under the treatment of antiandrogens [3].

Several major resistance pathways focus on androgen signaling, including AR overexpression and amplification, expression of AR mutants inducing promiscuity, response to non-androgen ligands, and constitutively active AR splice variants (AR-Vs) with ligand-independent activity. Intratumoral de novo biosynthesis of androgen and conversion of weak adrenal androgen into strong dihydrotestosterone (DHT) may also contribute to ligand-dependent AR activation.

\subsection{AR Amplification, Mutants, and Variants}

One of the most common events observed in PCa progressing from hormone- 
sensitive to castration-resistant form is AR gene amplification, occurring in 45\% [4]. In addition, a correlation between elevated expression of full-length AR or AR copy number gains resistant to second-generation antiandrogens has been documented [5]. This could be explained by an adaptive pharmacokinetic change, in which, the androgen is unable to achieve sufficient concentrations within the tumor, and thus, the increased intratumoral steroidogenesis overcomes the inhibitory effects of antiandrogens [6].

The mutations of AR are rare in untreated PCa patients and take place in approximately $15 \%$ of CRPC patients. Notably, the mutations of AR in PCa under the therapeutic pressure are responsible for such phenomena that conversion of the antiandrogens into AR agonists and progress of the early PCa to its lethal state, CRPC. Table 1 shows the confirmed AR mutants and the related drug resistance.

Over the last few years, along with AR mutations, constitutively active AR splice variants also promote the progression of PCa. As shown in Figure 2, Lu et al. decoded the AR splice variant transcripts [7]. Among them, two most common AR-Vs, AR-V7 and AR-v567es, were detected in $67.53 \%$ and $29.87 \%$ of CRPC samples, respectively [8]. AR-V7 lacking the AR LBD still retains the ability to activate transcriptions of its target genes. Antonarakis et al. found that AR-V7 conferred resistance to abiraterone and enzalutamide in metastatic CRPC, not to taxane [4] and cabazitaxel [9]. Constant expression of AR-v567es in the benign prostate tissues may induce epithelial hyperplasia and invasive adenocarcinoma [10].

\subsection{Tumor Microenvironment}

In hormone-sensitive, localized PCa, intraprostatic androgen has been found to categorize by $\sim 75 \%$ after the initial treatment, with residual androgen sufficient to drive the transcriptions of AR target genes [11]. However, in castration-resistant tumors, the elevated tumor androgen is characterized by the capability to activate the expression of AR and its target genes, by steroid synthesis, enzyme alterations that may increase de novo androgen level, or by the absorption of circulating hormone substrates and adrenal androgens into the tumor microenvironment [4] [12].

\section{New Drugs}

$\mathrm{AR}$ is encoded by the most complex gene in the nuclear steroid receptors, consisting of 4 domains (NTD, DBD, a hinge region, and LBD). An unsophisticated model of AR signaling includes 6 steps: 1) interaction between androgen and AR $\mathrm{LBD} ; 2)$ dissociation of heat shock proteins from AR; 3) dimerization of $A R$ and nuclear transport; 4) combination of AR and ARE located in the promoters of its target genes; 5) recruitment of AR co-activators to form AR complex; and 6) transcription and expression of AR target genes. In addition, AR phosphorylation, degradation, and interaction with co-regulators also play crucial roles in modulating the AR signaling pathway. Given the above criteria, 
Table 1. AR mutants and drug-resistance.

\begin{tabular}{|c|c|c|c|c|}
\hline AR mutations & Resistance to & Domain & Reference & Mechanisms \\
\hline E463G & abiraterone/dutasteride & NTD & {$[42]$} & unknown \\
\hline C595X & abiraterone & DBD & {$[42]$} & unknown \\
\hline S613F & abiraterone/dutasteride & DBD & {$[42]$} & unknown \\
\hline S646R & ketoconazole & Hinge region & {$[42]$} & unknown \\
\hline Q670R & hydroxyflutamide & Hinge region & {$[43]$} & unknown \\
\hline $\mathrm{I} 672 \mathrm{~T}$ & hydroxyflutamide & Hinge region & [43] & unknown \\
\hline $\mathrm{L} 701 \mathrm{H}$ & abiraterone, bisphenol A & LBD & [43] [45] & receptor promiscuity \\
\hline E709Y & bicalutamide & LBD & [46] & unknown \\
\hline V715M & $\begin{array}{l}\text { bicalutamide, } \\
\text { bisphenol A, } \\
\text { flutamide, } \\
\text { hydroxyflutamide }\end{array}$ & LBD & {$[10][47]$} & receptor promiscuity \\
\hline V731M & $\begin{array}{l}\text { bicalutamide, } \\
\text { flutamide }\end{array}$ & LBD & [48] & receptor promiscuity \\
\hline $\mathrm{W} 741 \mathrm{C} / \mathrm{L}$ & $\begin{array}{l}\text { abiraterone, } \\
\text { bicalutamide, } \\
\text { flutamide, } \\
\text { hydroxyflutamide }\end{array}$ & LBD & $\begin{array}{c}{[24]} \\
{[40][49]}\end{array}$ & $\begin{array}{l}\text { antagonist-to-agonist } \\
\text { switch }\end{array}$ \\
\hline M749I & bicalutamide & LBD & [45] & unknown \\
\hline V866M & abiraterone & LBD & {$[42]$} & unknown \\
\hline G872Q & cyproterone acetate & LBD & [45] & unknown \\
\hline E873Q & $\begin{array}{c}\text { abiraterone, } \\
\text { cyproterone acetate }\end{array}$ & LBD & [49] & receptor promiscuity \\
\hline H874Y/Q & $\begin{array}{c}\text { abiraterone, } \\
\text { bisphenol A, } \\
\text { flutamide, } \\
\text { hydroxyflutamide, } \\
\text { nilutamide }\end{array}$ & LBD & {$[40][44]$} & $\begin{array}{c}\text { receptor promiscuity, } \\
\text { antagonist-to-agonist } \\
\text { switch }\end{array}$ \\
\hline F876L & $\begin{array}{c}\text { ARN-509, } \\
\text { bicalutamide, } \\
\text { enzalutamide, } \\
\text { hydroxyflutamide, } \\
\text { MDV3100 }\end{array}$ & LBD & $\begin{array}{l}{[24][51]} \\
{[52][53]}\end{array}$ & $\begin{array}{l}\text { antagonist-to-agonist } \\
\text { switch }\end{array}$ \\
\hline T877A/S/C/G & $\begin{array}{c}\text { abiraterone, } \\
\text { bicalutamide, } \\
\text { bisphenol A, } \\
\text { cyproterone acetate, } \\
\text { hydroxyflutamide, } \\
\text { flutamide, } \\
\text { nilutamide, }\end{array}$ & LBD & $\begin{array}{c}{[10]} \\
{[44][48]}\end{array}$ & $\begin{array}{c}\text { receptor promiscuity, } \\
\text { antagonist-to-agonist } \\
\text { switch }\end{array}$ \\
\hline D879G & bicalutamide & LBD & [54] & $\begin{array}{l}\text { antagonist-to-agonist } \\
\text { switch (controversial) }\end{array}$ \\
\hline D880E & enzalutamide & LBD & [2] & unknown \\
\hline
\end{tabular}




\begin{tabular}{|c|c|c|c|c|}
\hline Continued & & & & \\
\hline L882I & enzalutamide & LBD & [2] & unknown \\
\hline S889G & $\begin{array}{l}\text { bicalutamide, } \\
\text { enzalutamide }\end{array}$ & LBD & [48] & $\begin{array}{l}\text { antagonist-to-agonist } \\
\text { switch }\end{array}$ \\
\hline $\mathrm{D} 891 \mathrm{H}$ & bicalutamide & LBD & [48] & $\begin{array}{l}\text { antagonist-to-agonist } \\
\text { switch }\end{array}$ \\
\hline E894K & enzalutamide & LBD & [2] & unknown \\
\hline M896T/V & $\begin{array}{l}\text { bicalutamide, } \\
\text { S-1 }\end{array}$ & LBD & [1] [40] [48] & $\begin{array}{c}\text { antagonist-to-agonist } \\
\text { switch }\end{array}$ \\
\hline
\end{tabular}

AR: Xq11-12

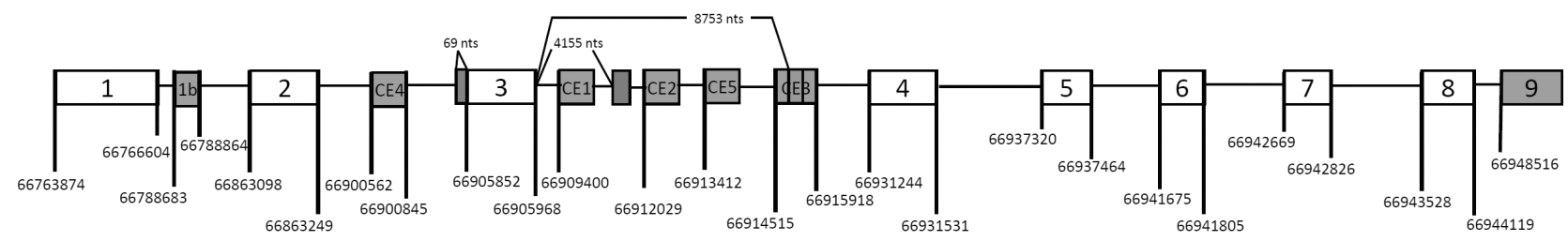

(a)

\begin{tabular}{|c|c|c|c|c|c|c|c|c|c|c|}
\hline$\underline{A R-V_{S}}$ & $\begin{array}{c}\text { Alternative } \\
\text { names } \\
\end{array}$ & $\begin{array}{c}\text { Transcriptional } \\
\text { activity }\end{array}$ & \multicolumn{8}{|c|}{ Transcripts } \\
\hline AR-FL & & $\begin{array}{l}\text { Ligand- } \\
\text { stimulated }\end{array}$ & 1 & 2 & 3 & 4 & 5 & 6 & 7 & 8 \\
\hline AR-45 & & Conditional & $1 \mathrm{~b}$ & 2 & 3 & 4 & 5 & 6 & 7 & 8 \\
\hline AR-23 & & $\begin{array}{l}\text { Ligand- } \\
\text { stimulated }\end{array}$ & 1 & 2 & 3 & 4 & 5 & 6 & 7 & 8 \\
\hline AR-V1 & AR4 & Conditional & 1 & 2 & 3 & CE1 & & & & \\
\hline AR-V2 & & Unknown & 1 & 2 & 3 & 3 & & $\mathrm{E} 1$ & & \\
\hline AR-V3 & AR $1 / 2 / 2 b$ & Constitutive & 1 & 2 & CE4 & 3 & & $\mathrm{E} 1$ & & \\
\hline AR-V4 & AR1/2/3/2b, AR5 & Constitutive & 1 & 2 & 3 & CE4 & & 3 & CE1 & \\
\hline AR-V5 & & Unknown & 1 & 2 & 3 & CE2 & & & & \\
\hline AR-V6 & & Unknown & 1 & 2 & 3 & CE2 & & & & \\
\hline AR-V7 & AR3 & Constitutive & 1 & 2 & 3 & CE3 & & & & \\
\hline AR-V8 & & Unknown & 1 & 2 & 3 & & & & & \\
\hline AR-V9 & & Conditional & 1 & 2 & 3 & CE5 & & & & \\
\hline AR-V10 & & Unknown & 1 & 2 & 3 & & & & & \\
\hline AR-V11 & & Unknown & 1 & 2 & 3 & & & & & \\
\hline AR-V12 & $A R^{\text {v567es }}$ & Constitutive & 1 & 2 & 3 & 4 & 8 & & 9 & \\
\hline AR-V13 & & Inactive & 1 & 2 & 3 & 4 & 5 & 6 & 9 & \\
\hline AR-V14 & & Unknown & 1 & 2 & 3 & 4 & 5 & 6 & 7 & 9 \\
\hline AR-8 & & Inactive & 1 & 3 & CE3 & & & & & \\
\hline
\end{tabular}

(b)

Figure 2. Decoding the androgen receptor splice variant transcripts. (a) AR gene structure with canonical and cryptic exon splice junctions marked according to GRCh37/hg19 human genome sequences; (b) Nomenclature, functional annotation, exon compositions, and variant-specific mRNA (4). 
investigators have been pursuing effective therapies for PCa, some already successful in the clinical application inducing drug resistance, which in turn necessitates the development of new drugs and clinical trials.

\subsection{Specific Drugs Binding with Different AR Domains}

The antiandrogens: enzalutamide, bicalutamide, and flutamide, primarily target the LBD of AR [13]. However, the LBD is non-conservative and susceptible to mutations; PCa cells might survive as AR signaling could be activated after mutation. The novel chemotherapeutic drugs targeting the conservative domains of $\mathrm{AR}$, combat $\mathrm{PCa}$ cells that alter to integrate with the tumor microenvironment.

3-(2,3-dihydro-1H-indol-2-yl)-1H-indole, VPC-13566, is one of binding function 3 (BF3) inhibitors that directly disturbs recruitment of AR cofactors, efficiently inactivates the AR signaling [10] [14] [15]. Additionally, the small molecule inhibitor EPI-001 [16] and its analog Epi-506 [17] can identify activation function-1 (AF-1) of N-terminal of AR binding with tubulin. A phase I/II trial testing Epi-506, is planned to open in the near future [17]. Furthermore, niphatenones bind to the $\mathrm{N}$-terminal of $\mathrm{AR}$, inhibit the transactivation of $\mathrm{AR}$ splice variants, and block the N/C interactions of AR [18].

\subsection{Inhibitors of AR Transcriptional Activity, Nuclear Translocation, and Degradation}

PCa cells survive from various therapies through AR amplification, mutation, splice variants, and elevated androgen concentration in the microenvironment. Scientists continually strive to find advanced treatments for PCa; for example, blocking AR transcription, interfering with AR nuclear localization, and promoting AR degradation that blocks the initiation of AR signaling pathways.

miRNA binding sites are found within the AR 3'-untranslated region (UTR) or coding regions. The miR-30 family members are direct AR inhibitors [19]. miR-124, as a tumor suppressor, limits the growth of PCa by targeting the AR transcripts and directly downregulating AR-V4 and AR-V7 [20]. miR-212 downregulates hnRNPH1 expression which decreases the expression of AR and AR-V7 in PCa cells [21]. PCGEM1 is a long non-coding RNA (lncRNA) that is often upregulated in PCa. Rescue experiments demonstrate that the re-expression of PCGEM1 lead to the upregulation of AR-V3 that is responsible for castration resistance [22]. Lin28 enhances the expression of AR-V7 by upregulating splicing factor hnRNPA1, and promotes the development of drug resistance [23].

The taxanes, cabazitaxel, and docetaxel, function at 3 aspects : stabilizing the microtubules, inhibiting the cell mitosis, and inducing apoptosis. They inhibit AR activity by interfering with AR nuclear translocation [24]. Taxanes effectively lessen the transcriptional activity of wild-type AR, but not those of AR-Vs lacking the microtubule-binding domain. In addition, ICRF187 and ICRF193, DNA topoisomerase II (Topo II) inhibitors, decrease transcription of the wild-type AR, mutant ARs (W741C and F876L), and AR-V7, reduced the AR recruitment 
to promoters of its target genes, and obstruct the nuclear localization [25]. CH5137291, an AR antagonist, inhibited the nuclear translocation of the wildtype AR, mutant ARs (W741C and T877A) [26]. Moreover, ODM-201, a nonsteroidal oral AR inhibitor, potently inhibits the interaction between androgen and AR LBD, and nuclear localization of AR. Importantly, ODM-201 is an effective antagonist for AR F876Lresistant to enzalutamide and ARN-509, and AR mutants (W741L, F876L, and T877A) resistant to bicalutamide and hydroxyflutamide. ODM-201 is currently in a phase 3 trial in CRPC [27]. The Src-Abl dual kinase inhibitor, PD180970, decreases AR-V7 expression, nuclear translocation, and androgen-independent transcription of target genes [28]. A thiohydantoin derivative, BAY 1024767, exhibits strong repressive activity to the wild-type AR and nine AR mutants by promoting nuclear localization in the absence of R1881 [29].

Galeterone, an AR antagonist, may inhibit CYP17 lyase activity and ubiquitylate AR protein. Galeterone selectively enhances the degradation of AR T878A. At low micromolar concentrations, it enhances AR protein degradation, whereas, at high concentrations, it could induce an endoplasmic reticulum (ER) stress response and may decrease AR translation. Based on results of the phase I/II trial, a phase III study on galeterone in CRPC is planned [30]. Niclosamide, an anti-helminthic drug, potentially suppresses the AR-V7 expression by enhancing its degradation, a phase I trial testing enzalutamide plus niclosamide in CRPC is being pursued [4] [31]. In addition, C-4 heteroaryl 13-cis-retinamides inhibit the AR transcriptional activity through degradation of the wild-type AR and AR-V7 in PCa cells [32]. ASC-J9, an AR degradation enhancer, may degrade both the wild-type AR and AR-V3 [33].

\subsection{AR Signaling Inhibitors}

In addition to truncating the initiation of AR signaling pathways, the scientists also design the other drugs targeting multiple key sites upstream and downstream of AR signaling, in order to further to reduce the AR-dependent signaling pathways for the development of PCa.

\subsubsection{Co-Activator Inhibitors}

Transcriptional machinery is complicated, at first, AR recruits RNA polymerase II and several co-activators, then AR complex binds to the trans-acting factors of its target genes to initiate transcriptional program [34]. Downregulation of histone deacetylase 1 or 3 (HDAC1 or HDAC3) may prevent the expression of AR target genes by interfering with the assembly of the AR complex. Unfortunately, a small phase II study about the HDAC inhibitor romidepsin failed to demonstrate sufficient activity in CRPC patients [35].

\subsubsection{AR Phosphorylation Inhibitors}

AR protein may be phosphorylated at tyrosine and serine/threonine residues. Etk/BMX tyrosine kinase and Src kinase may phosphorylate AR at Tyr-534, inducing AR nuclear localization, AR recruitment to the promoters, and tumor 
growth. AR Tyr-223 may be phosphorylated by Fer tyrosine kinase. Ack1 kinase phosphorylates AR at Tyr-267 and Tyr-363, promoting the recruitment of AR to trans-acting regions. Mutant ARs (Y267F and Y363F) inhibit Ack1-mediated AR transactivation and chromatin binding. In addition, cyclin-dependent kinase 1 or 9 (CDK1 or 9)-mediated phosphorylation of AR at Ser-81 associated with the AR-chromatin interaction [36]. JNK and p38 kinases phosphorylate AR at Ser-650, regulating the nuclear export of AR [37], whereas dephosphorylation by protein phosphatase 1 regulates the AR transcriptional activity and nuclear localization [38] [39].

\subsubsection{Upstream Inhibitors of AR Signaling}

The transcription factor GATA-binding protein 2 (GATA2) colocalizes with AR on chromatin to increase the recruitment of co-activators and formation of the AR complex. GATA2 directly promotes the expression of both the wild-type AR and AR-Vs; in turn, the expression of GATA2 is suppressed by AR and its ligands, suggesting a negative feedback regulatory loop [40].

Prostate cancer gene expression marker 1 (PCGEM1) interacts with splicing factors, hnRNP A1 and U2AF65, suggesting a role for PCGEM1 in alternative splicing. Androgen deprivation induces the expression of PCGEM1 and causes its accumulation in nuclear speckles. PCGEM1 regulates the competition between hnRNP A1 and U2AF65 for AR pre-mRNA. While the interaction of PCGEM1 with hnRNP A1 suppresses AR-V3 by exon skipping, its interaction with U2AF65 promotes AR-V3 by exonization [41].

\subsubsection{Downstream Inhibitors of AR Signaling}

The bromodomain and extra terminal (BET) inhibitor, ABBV-075, inhibited the androgen-stimulated transcription of AR target genes without significant effect on AR protein expression. ABBV-075 displayed a potent anti-proliferative activity in multiple models of resistance to second-generation antiandrogens and inhibited the activity of AR-V7 and AR F877L/L702H. This provides a promising therapeutic option for CRPC patients who have developed resistance to secondgeneration anti-androgens [42].

Transcriptomic profiling analysis of AR mutant (W741L) reveals 3 important genes, including RASD1 (Ras dexamethasone-induced 1), TIPARP (TCDD-inducible poly (ADP-ribose) polymerase), and $S G K 1$ (serum- and glucocorticoid-regulated kinase 1). SGK1 is upregulated in the KUCaPcells and a CRPC patient tissue containing AR mutant resistant to bicalutamide. GSK650394, a SGK1 inhibitor, may reduce the tumor growth induced by AR W741L. These results indicate that SGK1 is a key downstream protein of AR W741L, and SGK1 may be a new and efficient therapy for CRPC patients [43] [44].

\section{Perspective}

Previously, when scientists developed a treatment for $\mathrm{PCa}$, it was commonly expected to cure all the PCa patients. However, the accumulation of clinical experiences and advancement in medical knowledge led to the realization that a ma- 
jority of PCa patients were successfully treated initially; however, recurrence to incurable CRPC with malignant phenotypes occurred after several years. We have to accept the phenomena mentioned above that PCa can evolve to drug-resistant variant cells under the selection pressure. In order to effectively treat $\mathrm{PCa}$, it is essential to completely understand the mechanisms of PCa progression, and to develop novel drugs to counter resistance. This theory potentially explicates the smallest possibility of curing cancer, rendering an endless struggle with the disease.

Nowadays, investigators are attempting to develop new treatments effective against PCa in patients demonstrating resistance to clinical therapies. Additionally, a cocktail of various drugs and key enzyme treatments may increase the curative effect. The inhibitors targeting crucial enzymes or signaling pathway proteins may be more effective because the mutations of key enzymes or proteins induced by drug pressure are mortal to tumor or normal cells. Nevertheless, the side effects of these inhibitors are yet to be verified by several studies. These may be the developing direction of the PCa treatment in the near future. Moreover, all these therapies that have been successfully used in the clinic or ongoing trials do not consist of natural ingredients. The treatments cause an extra stimulus to the human body, which might not be an appropriate way to eliminate PCa. Thus, if a therapeutic method cannot bring extra stimulus, simultaneously remove the tumor, or make the body to eliminate the tumor actively, it will be the most yearned treatment. It will be the ultimate goal of developing PCa treatment.

\section{Sources of Support in the Form of Grants}

This work was supported by Zhejiang Provincial Science Technology Program of China (2013C33101), Zhejiang medical platform program (2015RCA023).

\section{References}

[1] Chan, S.C. and Dehm, S.M. (2014) Constitutive Activity of the Androgen Receptor. Advances in Pharmacology, 70, 327-366.

[2] Dalal, K., Roshan-Moniri, M., Sharma, A., Li, H., Ban, F., et al. (2014) Selectively Targeting the DNA-Binding Domain of the Androgen Receptor as a Prospective Therapy for Prostate Cancer. Journal of Biological Chemistry, 289, 26417-26429. https://doi.org/10.1074/jbc.M114.553818

[3] Sartor, A.O., Tangen, C.M., Hussain, M.H., Eisenberger, M.A., Parab, M., et al. (2008) Antiandrogen Withdrawal in Castrate-Refractory Prostate Cancer: A Southwest Oncology Group Trial (SWOG 9426). Cancer, 112, 2393-2400. https://doi.org/10.1002/cncr.23473

[4] Schweizer, M.T. and Yu, E.Y. (2015) Persistent Androgen Receptor Addiction in Castration-Resistant Prostate Cancer. Journal of Hematology \& Oncology, 8, 128. https://doi.org/10.1186/s13045-015-0225-2

[5] Azad, A.A., Volik, S.V., Wyatt, A.W., Haegert, A., Le Bihan, S., et al. (2015) Androgen Receptor Gene Aberrations in Circulating Cell-Free DNA, Biomarkers of Therapeutic Resistance in Castration-Resistant Prostate Cancer. Clinical Cancer Research, 21, 2315-2324. https://doi.org/10.1158/1078-0432.CCR-14-2666 
[6] Tamae, D., Mostaghel, E., Montgomery, B., Nelson, P.S., Balk, S.P., et al. (2015) The DHEA-Sulfate Depot Following P450c17 Inhibition Supports the Case for AKR1C3 Inhibition in High Risk Localized and Advanced Castration Resistant Prostate Cancer. Chemico-Biological Interactions, 234, 332-338.

[7] Lu, C. and Luo, J. (2013) Decoding the Androgen Receptor Splice Variants. Translational Andrology and Urology, 2, 178-186.

[8] Liu, X., Ledet, E., Li, D., Dotiwala, A., Steinberger, A., et al. (2016) A Whole Blood Assay for AR-V7 and $\mathrm{AR}^{\mathrm{v} 567 \mathrm{es}}$ in Patients with Prostate Cancer. The Journal of Urology, 196, 1758-1763. https://doi.org/10.1016/j.juro.2016.06.095

[9] Onstenk, W., Sieuwerts, A.M., Kraan, J., Van, M., Nieuweboer, A.J., et al. (2015) Efficacy of Cabazitaxel in Castration-Resistant Prostate Cancer Is Independent of the Presence of AR-V7 in Circulating Tumor Cells. European Urology, 68, 939-945. https://doi.org/10.1016/j.eururo.2015.07.007

[10] Liu, G., Sprenger, C., Sun, S., Epilepsia, K.S., Haugk, K., et al. (2013) AR Variant $\mathrm{Ar}^{\mathrm{r} 567 \mathrm{es}}$ Induces Carcinogenesis in a Novel Transgenic Mouse Model of Prostate Cancer. Neoplasia, 15, 1009-1017. https://doi.org/10.1593/neo.13784

[11] Mostaghel, E.A., Page, S.T., Lin, D.W., Fazli, L., Coleman, I.M., et al. (2007) Intraprostatic Androgens and Androgen-Regulated Gene Expression Persist after Testosterone Suppression, Therapeutic Implications for Castration-Resistant Prostate Cancer. Cancer Research, 67, 5033-5041. https://doi.org/10.1158/0008-5472.CAN-06-3332

[12] Liu, C., Lou, W., Zhu, Y., Yang, J.C., Nadiminty, N., et al. (2015) Intracrine Androgens and AKR1C3 Activation Confer Resistance to Enzalutamide in Prostate Cancer. Cancer Research, 75, 1413-1422. https://doi.org/10.1158/0008-5472.CAN-14-3080

[13] Tian, X., He, Y. and Zhou, J. (2015) Progress in Antiandrogen Design Targeting Hormone Binding Pocket to Circumvent Mutation Based Resistance. Frontiers in Pharmacology, 6, 57.

[14] Munuganti, R.S., Hassona, M.D., Leblanc, E., Frewin, K., Singh, K., et al. (2014) Identification of a Potent Antiandrogen That Targets the BF3 Site of the Androgen Receptor and Inhibits Enzalutamide-Resistant Prostate Cancer. Chemistry \& Biology, 21, 1476-1485.

[15] Jehle, K., Cato, L., Neeb, A., Muhle-Goll, C., Jung, N., et al. (2014) Coregulator Control of Androgen Receptor Action by a Novel Nuclear Receptor-Binding Motif. Journal of Biological Chemistry, 289, 8839-8851. https://doi.org/10.1074/jbc.M113.534859

[16] Brand, L.J., Olson, M.E., Ravindranathan, P., Guo, H., Kempema, A.M., et al. (2015) EPI-001 Is a Selective Peroxisome Proliferator-Activated Receptor-Gamma Modulator with Inhibitory Effects on Androgen Receptor Expression and Activity in Prostate Cancer. Oncotarget, 6, 3811-3824. https://doi.org/10.18632/oncotarget.2924

[17] Antonarakis, E.S., Chandhasin, C., Osbourne, E., Luo, J., Sadar, M.D., et al. (2016) Targeting the N-Terminal Domain of the Androgen Receptor: A New Approach for the Treatment of Advanced Prostate Cancer. Oncologist, 21, 1427-1435. https://doi.org/10.1634/theoncologist.2016-0161

[18] Banuelos, C.A., Lal, A., Tien, A.H., Shah, N., Yang, Y.C., et al. (2014) Characterization of Niphatenones That Inhibit Androgen Receptor N-Terminal Domain. PLoS ONE, 9, e107991. https://doi.org/10.1371/journal.pone.0107991

[19] Kumar, B., Khaleghzadegan, S., Mears, B., Hatano, K., Kudrolli, T.A., et al. (2016) Identification of miR-30b-3p and miR-30d-5p as Direct Regulators of Androgen 
Receptor Signaling in Prostate Cancer by Complementary Functional microRNA Library Screening. Oncotarget, 7, 72593-72607.

[20] Shi, X.B., Ma, A.H., Xue, L., Li, M., Nguyen, H.G., et al. (2015) miR-124 and Androgen Receptor Signaling Inhibitors Repress Prostate Cancer Growth by Downregulating Androgen Receptor Splice Variants, EZH2, and Src. Cancer Research, 75, 5309-5317. https://doi.org/10.1158/0008-5472.CAN-14-0795

[21] Yang, Y., Jia, D., Kim, H., Abd Elmageed, Z.Y., Datta, A., et al. (2016) Dysregulation of miR-212 Promotes Castration Resistance through hnRNPH1-Mediated Regulation of AR and AR-V7, Implications for Racial Disparity of Prostate Cancer. Clinical Cancer Research, 22, 1744-1756. https://doi.org/10.1158/1078-0432.CCR-15-1606

[22] Ho, T.T., Huang, J., Zhou, N., Zhang, Z., Koirala, P., et al. (2016) Regulation of PCGEM1 by p54/nrb in Prostate Cancer. Scientific Reports, 6, Article No. 34529. https://doi.org/10.1038/srep34529

[23] Tummala, R., Nadiminty, N., Lou, W., Evans, C.P. and Gao, A.C. (2016) Lin28 Induces Resistance to Anti-Androgens via Promotion of AR Splice Variant Generation. The Prostate, 76, 445-455. https://doi.org/10.1002/pros.23134

[24] Antonarakis, E.S., Lu, C., Luber, B., Wang, H., Chen, Y., et al. (2015) Androgen Receptor Splice Variant 7 and Efficacy of Taxane Chemotherapy in Patients with Metastatic Castration-Resistant Prostate Cancer. JAMA Oncology, 1, 582-591. https://doi.org/10.1001/jamaoncol.2015.1341

[25] Li, H., Xie, N., Gleave, M.E. and Dong, X. (2015) Catalytic Inhibitors of DNA Topoisomerase II Suppress the Androgen Receptor Signaling and Prostate Cancer Progression. Oncotarget, 6, 20474-20484. https://doi.org/10.18632/oncotarget.4105

[26] Ishikura, N., Kawata, H., Nishimoto, A., Nakamura, R., Tsunenari, T., et al. (2015) CH5137291, an Androgen Receptor Nuclear Translocation-Inhibiting Compound, Inhibits the Growth of Castration-Resistant Prostate Cancer Cells. International Journal of Oncology, 46, 1560-1572.

[27] Moilanen, A.M., Riikonen, R., Oksala, R., Ravanti, L., Aho, E., et al. (2015) Discovery of ODM-201, a New-Generation Androgen Receptor Inhibitor Targeting Resistance Mechanisms to Androgen Signaling-Directed Prostate Cancer Therapies. Scientific Reports, 5, Article No. 12007. https://doi.org/10.1038/srep12007

[28] Szafran, A.T., Stephan, C., Bolt, M., Mancini, M.G., Marcelli, M., et al. (2017) High-Content Screening Identifies Src Family Kinases as Potential Regulators of AR-V7 Expression and Androgen-Independent Cell Growth. The Prostate, 77, 8293. https://doi.org/10.1002/pros.23251

[29] Sugawara, T., Lejeune, P., Köhr, S., Neuhaus, R., Faus, H., et al. (2016) BAY 1024767 Blocks Androgen Receptor Mutants Found in Castration-Resistant Prostate Cancer Patients. Oncotarget, 7, 6015-6028.

[30] Yu, Z., Cai, C., Gao, S., Simon, N.I., Shen, H.C. and Balk, S.P. (2014) Galeterone Prevents Androgen Receptor Binding to Chromatin and Enhances Degradation of Mutant Androgen Receptor. Clinical Cancer Research, 20, 4075-4085. https://doi.org/10.1158/1078-0432.CCR-14-0292

[31] Liu, C., Lou, W., Zhu, Y., Nadiminty, N., Schwartz, C.T., et al. (2014) Niclosamide Inhibits Androgen Receptor Variants Expression and Overcomes Enzalutamide Resistance in Castration-Resistant Prostate Cancer. Clinical Cancer Research, 20, 3198-3210. https://doi.org/10.1158/1078-0432.CCR-13-3296

[32] Mbatia, H.W., Ramalingam, S., Ramamurthy, V.P., Martin, M.S., Kwegyir-Afful, A.K., et al. (2015) Novel C-4 Heteroaryl 13-cis-Retinamide Mnk/AR Degrading Agents Inhibit Cell Proliferationand Migration and Induce Apoptosis in Human 
Breast and Prostate Cancer Cells and Suppress Growth of MDA-MB-231 Human Breast and CWR22Rv1 Human Prostate Tumor Xenografts in Mice. Journal of Medicinal Chemistry, 58, 1900-1914. https://doi.org/10.1021/jm501792c

[33] Yamashita, S., Lai, K.P., Chuang, K.L., Xu, D., Miyamoto, H., et al. (2012) ASC-J9 Suppresses Castration-Resistant Prostate Cancer Growth through Degradation of Full-Length and Splice Variant Androgen Receptors. Neoplasia, 14, 74-83. https://doi.org/10.1593/neo.111436

[34] Robinson, D., Van Allen, E.M., Wu, Y.M., Schultz, N., Lonigro, R.J., et al. (2015) Integrative Clinical Genomics of Advanced Prostate Cancer. Cell, 161, 1215-1228. https://doi.org/10.1016/j.cell.2015.05.001

[35] Welsbie, D.S., Xu, J., Chen, Y., Borsu, L., Scher, H.I., et al. (2009) Histone Deacetylases Are Required for Androgen Receptor Function in Hormone-Sensitive and Castrate-Resistant Prostate Cancer. Cancer Research, 69, 958-966.

https://doi.org/10.1158/0008-5472.CAN-08-2216

[36] Gordon, V., Bhadel, S., Wunderlich, W., Zhang, J., Ficarro, S.B., et al. (2010) CDK9 Regulates AR Promoter Selectivity and Cell Growth through Serine 81 Phosphorylation. Molecular Endocrinology, 24, 2267-2280.

https://doi.org/10.1210/me.2010-0238

[37] Gioeli, D., Black, B.E., Gordon, V., Spencer, A., Kesler, C.T., et al. (2006) Stress Kinase Signaling Regulates Androgen Receptor Phosphorylation, Transcription, and Localization. Molecular Endocrinology, 20, 503-515. https://doi.org/10.1210/me.2005-0351

[38] Karaca, M., Liu, Y., Zhang, Z., De Silva, D., Parker, J.S., et al. (2015) Mutation of Androgen Receptor N-Terminal Phosphorylation Site Tyr-267 Leads to Inhibition of Nuclear Translocation and DNA Binding. PLoS ONE, 10, e0126270. https://doi.org/10.1371/journal.pone.0126270

[39] Chen, S., Kesler, C.T., Paschal, B.M. and Balk, S.P. (2009) Androgen Receptor Phosphorylation and Activity Are Regulated by an Association with Protein Phosphatase 1. Journal of Biological Chemistry, 284, 25576-25584. https://doi.org/10.1074/jbc.M109.043133

[40] He, B., Lanz, R.B., Fiskus, W., Geng, C., Yi, P., et al. (2014) GATA2 Facilitates Steroid Receptor Coactivator Recruitment to the Androgen Receptor Complex. Proceedings of the National Academy of Sciences of the United States of America, 11, 18261-18266. https://doi.org/10.1073/pnas.1421415111

[41] Zhang, Z., Zhou, N., Huang, J., Ho, T.T., Zhu, Z., et al. (2016) Regulation of Androgen Receptor Splice Variant AR3 by PCGEM1. Oncotarget, 7, 15481-15491.

[42] Faivre, E.J., Wilcox, D., Lin, X., Hessler, P., Torrent, M., et al. (2017) Exploitation of Castration-Resistant Prostate Cancer Transcription Factor Dependencies by the Novel BET Inhibitor ABBV-075. Molecular Cancer Research, 15, 35-44. https://doi.org/10.1158/1541-7786.MCR-16-0221

[43] Buchanan, G., Yang, M., Harris, J.M., Nahm, H.S., Han, G., et al. (2001) Mutations at the Boundary of the Hinge and Ligand Binding Domain of the Androgen Receptor Confer Increased Transactivation Function. Molecular Endocrinology, 15, 46-56. https://doi.org/10.1210/mend.15.1.0581

[44] Brooke, G.N., Parker, M.G. and Bevan, C.L. (2008) Mechanisms of Androgen Receptor Activation in Advanced Prostate Cancer, Differential Co-Activator Recruitment and Gene Expression. Oncogene, 27, 2941-2950. https://doi.org/10.1038/sj.onc.1210955

[45] Lorente, D., Mateo, J., Zafeiriou, Z., Smith, A.D., Sandhu, S., et al. (2015) Switching and Withdrawing Hormonal Agents for Castration-Resistant Prostate Cancer. Na- 
ture Reviews Urology, 12, 37-47. https://doi.org/10.1038/nrurol.2014.345

[46] Malik, R., Khan, A.P., Asangani, I.A., Cieślik, M., Prensner, J.R., et al. (2015) Targeting the MLL Complex in Castration-Resistant Prostate Cancer. Nature Medicine, 21, 344-352. https://doi.org/10.1038/nm.3830

[47] Evaul, K., Li, R., Papari-Zareei, M., Auchus, R.J. and Sharifi, N. (2010) 3beta-Hydroxysteroid Dehydrogenase Is a Possible Pharmacological Target in the Treatment of Castration-Resistant Prostate Cancer. Endocrinology, 151, 3514-3520. https://doi.org/10.1210/en.2010-0138

[48] Lallous, N., Volik, S.V., Awrey, S., Leblanc, E., Tse, R., et al. (2016) Functional Analysis of Androgen Receptor Mutations That Confer Anti-Androgen Resistance Identified in Circulating Cell-Free DNA from Prostate Cancer Patients. Genome Biology, 17, 10. https://doi.org/10.1186/s13059-015-0864-1

[49] Asangani, I.A., Dommeti, V.L., Wang, X., Malik, R., Cieslik, M., et al. (2014) Therapeutic Targeting of BET Bromodomain Proteins in Castration-Resistant Prostate Cancer. Nature, 510, 278-282. https://doi.org/10.1038/nature13229

[50] Chen, G., Wang, X., Zhang, S., Lu, Y., Sun, Y., et al. (2005) Androgen Receptor Mutants Detected in Recurrent Prostate Cancer Exhibit Diverse Functional Characteristics. The Prostate, 63, 395-406. https://doi.org/10.1002/pros.20191

[51] Claessens, F., Helsen, C., Prekovic, S., Van den Broeck, T., Spans, L., et al. (2014) Emerging Mechanisms of Enzalutamide Resistance in Prostate Cancer. Nature Reviews Urology, 11, 712-716. https://doi.org/10.1038/nrurol.2014.243

[52] Gustafson, J.L., Neklesa, T.K., Cox, C.S., Roth, A.G., Buckley, D.L., et al. (2015) Small-Molecule-Mediated Degradation of the Androgen Receptor through Hydrophobic Tagging. Angewandte Chemie International Edition, 54, 9659-9662. https://doi.org/10.1002/anie.201503720

[53] Wright, J.L., Kwon, E.M., Ostrander, E.A., Montgomery, R.B., Lin, D.W., et al. (2011) Expression of SLCO Transport Genes in Castration-Resistant Prostate Cancer and Impact of Genetic Variation in SLCO1B3 and SLCO2B1 on Prostate Cancer Outcomes. Cancer Epidemiology, Biomarkers \& Prevention, 20, 619-627. https://doi.org/10.1158/1055-9965.EPI-10-1023

[54] Richards, J., Lim, A.C., Hay, C.W., Taylor, A.E., Wingate, A., et al. (2012) Interactions of Abiraterone, Eplerenone, and Prednisolone with Wild-Type and Mutant Androgen Receptor, Arationale for Increasing Abiraterone Exposure or Combining with MDV3100. Cancer Research, 72, 2176-2182. https://doi.org/10.1158/0008-5472.CAN-11-3980 


\section{Abbreviations}

\begin{tabular}{|c|c|}
\hline $\mathrm{PCa}$ & Prostate cancer \\
\hline $\mathrm{ADT}$ & Androgen deprivation therapy \\
\hline AR & Androgen receptor \\
\hline CRPC & Castration-resistant $\mathrm{PCa}$ \\
\hline DBD & DNA-binding domain \\
\hline LBD & Ligand-binding domain \\
\hline ARE & Androgen-responsive elements \\
\hline AR-Vs & AR splice variants \\
\hline DHT & Dihydrotestosterone \\
\hline BF3 & Binding function 3 \\
\hline AF-1 & Activation function-1 \\
\hline UTR & Untranslated region \\
\hline $\operatorname{lncRNA}$ & Long non-coding RNA \\
\hline Topo II & Topoisomerase II \\
\hline ER & Endoplasmic reticulum \\
\hline HDAC1 or HDAC 3 & Histone deacetylase 1 or 3 \\
\hline CDK1 or 9 & Cyclin-dependent kinase 1 or 9 \\
\hline GATA2 & GATA-binding protein 2 \\
\hline PCGEM1 & Prostate cancer gene expression marker 1 \\
\hline BET & Bromodomain and extra terminal \\
\hline RASD1 & Ras dexamethasone-induced 1 \\
\hline TIPARP & TCDD-inducible poly (ADP-ribose) polymerase \\
\hline SGK1 & Serum- and glucocorticoid-regulated kinase 1 \\
\hline
\end{tabular}

\section{Scientific Research Publishing}

Submit or recommend next manuscript to SCIRP and we will provide best service for you:

Accepting pre-submission inquiries through Email, Facebook, LinkedIn, Twitter, etc. A wide selection of journals (inclusive of 9 subjects, more than 200 journals)

Providing 24-hour high-quality service

User-friendly online submission system

Fair and swift peer-review system

Efficient typesetting and proofreading procedure

Display of the result of downloads and visits, as well as the number of cited articles Maximum dissemination of your research work

Submit your manuscript at: http://papersubmission.scirp.org/

Or contact ijcm@scirp.org 